\title{
Effects of andrographolide on postoperative cognitive dysfunction and the association with NF-кB/MAPK pathway
}

\author{
YONGBO DING ${ }^{1,2^{*}}$, CUNXIAN SHI $^{1,2^{*}}$, LINJING CHEN $^{3}$, PILIANG MA ${ }^{4}$, \\ KEZHONG LI ${ }^{1,2}$, JIN JIN ${ }^{2}$, QINGFENG ZHANG ${ }^{2}$ and AIZHI LI ${ }^{2}$ \\ ${ }^{1}$ Department of Anesthesiology, School of Medicine, Shandong University, Jinan, Shandong 250012; \\ Departments of ${ }^{2}$ Anesthesiology and ${ }^{3}$ Operating Room, The Affiliated Yantai Yuhuangding Hospital of Qingdao University, \\ Yantai, Shandong 264000; ${ }^{4}$ Department of Anesthesiology, Qingdao Hiser Medical Center, \\ Qingdao, Shandong 266033, P.R. China
}

Received June 9, 2017; Accepted September 7, 2017

DOI: $10.3892 / 01.2017 .7088$

\begin{abstract}
The present study investigated the effects of andrographolide on postoperative cognitive dysfunction (POCD) in aged rats to gaininsight of the underlying mechanism, which may provide theoretical basis for the clinical application of andrographolide to prevent POCD in older patients. Thirty aged male rats were randomly assigned to 3 groups: Control, model and andrographolide groups. The Morris water maze test was used to examine the spatial memory and learning ability of the rats postoperatively. The histological alterations of neuronal cells in the hippocampus were visualized by H\&E staining. The serum levels of neuron-specific enolase (NSE), human soluble protein-100 $\beta$ (S-100 $\beta$ ) and the inflammation factors of interluekin (IL)-1 $\beta$, IL-6 and TNF- $\alpha$ involved in the nuclear factor $\kappa \mathrm{B}(\mathrm{NF}-\kappa \mathrm{B}) /$ mitogen-activated protein kinase (MAPK) signaling pathway were detected by ELISA. The $\mathrm{NF}-\kappa \mathrm{B} / \mathrm{MAPK}$ signaling pathway-associated proteins in rat serum were detected by western blotting. Following andrographolide treatment, the rats significantly gained learning ability after surgery. Is it ameliorated hippocampal neuronal injury in rats following surgery. Andrographolide decreased NSE, S-100 $\beta$, and the inflammation factors, IL-6, IL-1 $\beta$ and TNF- $\alpha$ in serum. Andrographolide reduced NF- $\kappa$ B/MAPK
\end{abstract}

Correspondence to: Dr Cunxian Shi, Department of Anesthesiology, The Affiliated Yantai Yuhuangding Hospital of Qingdao University, 20 Yuhuangding East Road, Zhifu, Yantai, Shandong 264000, P.R. China

E-mail: shicunxian@163.com

Dr Kezhong Li, Department of Anesthesiology, School of Medicine, Shandong University, 44 Wenhua West Road, Jinan, Shandong 250012, P.R. China

E-mail: dingyongboo@hotmail.com

*Contributed equally

Key words: Morris water maze test, aged rats, neuron-specific enolase, human soluble protein-100 $\beta, \mathrm{NF}-\kappa \mathrm{B} / \mathrm{MAPK}$ pathway-associated protein expression. Andrographolide ameliorated POCD in aged rats following surgery. The underlying mechanism may be associated with the downregulation the inflammatory factors and NF- $\kappa \mathrm{B} / \mathrm{MAPK}$-associated protein expression.

\section{Introduction}

Postoperative cognitive dysfunction (POCD) is a recognized clinical phenomenon of cognitive deficiency after anesthesia and surgery (1). It was firstly described by Bedford in 1955 under the designation 'adverse cerebral effects of anesthesia on old people' (2). POCD exhibits high morbidity in the advanced ages of patients and is well documented by dementia-like symptoms, for instance, memory weakening, loss of attention, an incompetence to plan, and difficulty to shift between tasks (3). It has been shown that POCD occurs following all kinds of surgery preferably with higher incidence in cardiac surgery than non-cardiac surgery (4-6). Once occurrence, POCD typically will last for weeks, months and even longer, which are presumably considered the early lesions of Alzheimer's disease (AD), seriously affecting the patient's postoperative rehabilitation and long-term quality of life $(7,8)$. Till now, there is no treatment to completely cure the POCD patients. Though mounting evidences suggested the anesthesia and surgery may be the main cause, aging is the only definitive risk factor (9), the exact mechanism of POCD development remains largely unclear.

Several mechanisms were proposed recently. It is well known that the inflammation occurred in the process of surgery and trauma followed by POCD persistence (10). Emerging evidences suggested the involvement of inflammatory processes might be a likely pathogenic mechanism for POCD, and cytokines like interluekin (IL)-1 $\beta$ have been associated $(4,11)$. In rodent studies, postoperative increases in comprehensive and hippocampal pro-inflammatory cytokines and microglial activation have been concomitant with postoperative impairment of spatial, contextual learning and memory (12-16). Additionally, suppression of central pro-inflammatory cytokine signaling was revealed to mitigate postoperative memory diminishing in rodents $(13-15,17)$. The 
peripheral inflammatory reaction to surgery and POCD in patients was confirmed associated (18). Inflammatory intermediaries in the brain may impact learning and memory directly, but also indirectly by hindering intraneuronal signaling pathways (19). Pro-inflammatory cytokines can perhaps impede brain-derived neurotrophic factor (BDNF)-signaling via activation of p38 mitogen-activated protein kinase (MAPK) and nuclear factor $\kappa \mathrm{B}(\mathrm{NF}-\kappa \mathrm{B})$, resulting in abridged neurogenesis and neuronal plasticity (12,19-22).

Andrographolide is a natural diterpenoid whose major constituent is andrographis paniculata, which has been used in China for long time. Previous studies reported that andrographolide holds antibacterial, anti-inflammatory and antiviral activities (23). It is known that multiple inflammatory stimuli caused MAPK and the transcription factor NF- $\kappa \mathrm{B}$ activation, which modulates TNF- $\alpha$, IL- $1 \beta$, and IL- 6 expression in many inflammatory disease progressions (24). Previously few studies report the effect of andrographolideon the animal upon stress environment. Peng et al claimed andrographolide sulfonate markedly suppressed the activation of MAPK as well as p65 subunit of NF- $\kappa \mathrm{B}$ in lipopolysaccharide (LPS)-induced acute lung injury in mice (24). Zhu et al addressed that andrographolide can alleviate LPS-induced sepsis and acute lung injury (25). Andrographolide can significantly reduce $\mathrm{NF}-\kappa \mathrm{B}$ and NLRP3 inflammasome activation and finally alleviated the symptoms in ovalbumin-treated mice (24). In addition, andrographolide could deter the activation of ERK1/2, p38 MAPK and NK- $\mathrm{NB}$ induced by oxidized low density lipoprotein in macrophage foam cells, which might be one of the potential mechanisms in avoiding atherosclerosis (26).

Though several studies attempted to elucidate the underlying mechanism of POCD in different models and species, there is no reference to report the effects of andrographolide treatment on POCD after surgery only, and the association with NF- $\mathrm{B} / \mathrm{MAPK}$ pathway study after general anaesthesia (GA) and regional anaesthesia (RA). Herein, we aimed to investigate the morphologic changes of hippocampal neurons, inflammatory mediators via MAPKs and NF- $\mathrm{B}$ signaling pathways after treatment with andrographolide, and attempt to gain insight of the underlying mechanisms, subsequently, to develop a new therapeutic approach for the advanced age patients clinically.

\section{Materials and methods}

Ethics statement. All the animal work was conducted strictly under the regulation of the Guide for the Care and Use of Laboratory Animals of the National Institutes of Health. The protocol was approved by the Ethics Committee of Animal Experiments of the Ethics Committee of the Affiliated Yantai Yuhuangding Hospital of Qingdao University (Yantai, China). All surgeries were performed under diethyl ether anesthesia and all efforts were made timely to reduce the pain and suffering as much as possible.

Animals. The rats (specific pathogen free) were purchased from the Institute of Laboratory Animal Life Sciences (Shanghai, China). All rats were kept in temperature at $21-23^{\circ} \mathrm{C}$ with humidity of $60 \%$ and under a $12 / 12 \mathrm{~h}$ light/dark cycle. Rats freely accessed to drinking water and food.
Thirty healthy Sprague-Dawley male, aged 25 months and weighing 250-300 g rats were randomly divided into 3 groups ( $n=10$ in each group), control group, model group and andrographolide group. All aspects of surgery are in strict accordance with the principle of aseptic. All the necessary components are preassembled on a sterile tray ready for use. The rats were fasted with water and food $8 \mathrm{~h}$ prior to surgery. The surgery area was disinfected and kept sterile. The rats were anesthetized with diethyl ether globally and 5\% lidocaine for local infiltration anesthesia, and placed on a heating pad to prevent hypothermia. The left anterior longitudinal incision was made and the layers were stratified to cut the abdominal wall into the abdominal cavity. The rats in control group and andrographolide group were processed as below. Basically, peripheral ligament of the spleen was released during intraoperative surgery and then the abdomen incision was sutured layer by layer. The model group was processed as following. Peripheral ligament of the spleen was released, the whole blood vessels were ligated and the splenectomy was operated. The side spleen was cut off and the abdomen incision was sutured layer by layer. The rats were freely accessed to $20 \%$ glucose drinking after $12 \mathrm{~h}$ surgery and freely accessed to food after $24 \mathrm{~h}$ surgery. At $24 \mathrm{~h}$ post-surgery, the control group and andrographolide group were feeding distilled water $(10 \mathrm{ml} / \mathrm{kg})$ and andrographolide $(10 \mathrm{mg} / \mathrm{kg})$ (Sigma-Aldrich, St. Louis, MO, USA), separately, once a day for 7 days.

Morris water maze test (MWM). Spatial learning, spatial memory and cognitive flexibility were assessed under the protocol as described previously (12). Prior to behavior testing, the rats were allowed an adaptation period for 3 days. Then the positioning navigation test was conducted and lasted for 6 days on the rats. Briefly, the rats were placed facing the swimming pool wall, from different places and random directions, 4 times in a day. The swimming trajectory was recorded by the automatic camera system and analyzed with the software. The maximal time limit for the rats to find the platform was setup as $60 \mathrm{sec}, 5 \mathrm{sec}$ after landing on the stage for the rats regarding as a successful searching of the hidden platform, then the camera system automatically stopped recording. The rats were allowed to stay on the platform for $15 \mathrm{sec}$ to observe the surrounding cues and then to start the next training. All the rats were ensured the same training interval. If the rat fails to find a hidden platform within $60 \mathrm{sec}$, the camera system automatically stopped recording and the escape latency (the period from getting into the water to successfully find the hidden platform) was recorded as $60 \mathrm{sec}$. The rats were induced to locate the platform and allowed to stay on the platform for $15 \mathrm{sec}$. The positioning navigation test was conducted on the 7th day. Generally, the platform was removed, and then the rat was placed into the water from the two random water points (except the platform quadrant) and the swimming trajectory was recorded in $60 \mathrm{sec}$. The average of the 2 times was taken as the result of the positioning navigation test. The parameters of the automatic analysis system included the escape latency, the number of the cross-platform, the platform retention time, and the swimming distance.

Samples collection. After the MMW test, the rats were anesthetized by intraperitoneal injection and immediately decapitated. The whole brain was dissected and the blood was 
Table I. Comparison of the memory ability in rats in each group.

\begin{tabular}{lccc}
\hline Group & Cross-platform number & Platform quadrant dwelling time (sec) & Swimming distance (cm) \\
\hline Control & $4.55 \pm 0.37$ & $50.39 \pm 4.82$ & $7.04 \pm 0.49$ \\
Model & $1.63 \pm 0.29^{\mathrm{a}}$ & $24.67 \pm 2.53^{\mathrm{a}}$ & $16.32 \pm 1.45^{\mathrm{a}}$ \\
Andrographolide & $3.17 \pm 0.32^{\mathrm{a}, \mathrm{b}}$ & $32.81 \pm 3.44^{\mathrm{a}, \mathrm{b}}$ & $10.18 \pm 0.87^{\mathrm{a}, \mathrm{b}}$ \\
\hline
\end{tabular}

${ }^{\mathrm{a}} \mathrm{P}<0.05$ vs. control group; ${ }^{\mathrm{b}} \mathrm{P}<0.05$ vs. model group.

harvested. Some of the brains were quickly fixed in $4 \%$ paraformaldehyde for later $\mathrm{H} \& \mathrm{E}$ staining. The remaining brain tissue was frozen in $-80^{\circ} \mathrm{C}$ for western blot detection (Thermo Fisher Scientific, Inc., Waltham, MA, USA). The blood was spun down for $10 \mathrm{~min}$ at 4,000 r/min, and the supernatant was saved at $-20^{\circ} \mathrm{C}$ for enzyme-linked immunosorbent assay (ELISA).

$H \& E$ staining of hippocampal neurons. The brain was fixed in $4 \%$ paraformaldehyde for $24 \mathrm{~h}$, after routine flushing, dehydration, paraffin embedding and sectioning (Leica Microsystems $\mathrm{GmbH}$, Wetzlar, Germany), the sections were stained with hematoxylin and eosin. In the hippocampal CA1 area, five randomly selected microscopic fields of neuronal cells in hippocampus of brain were observed under light microscope (Olympus Corporation, Tokyo, Japan).

ELISA. The levels of neuron-specific enolase (NSE), human soluble protein-100 $\beta$ (S-100 $\beta$ ) and the contents of IL-1 $\beta$, IL-6, TNF- $\alpha$ involved in NF- $\kappa \mathrm{B} / \mathrm{MAPK}$ signaling pathways were measured by ELISA. Briefly, after thawing of the cryopreserved serum samples at room temperature, the serum was centrifuged at 1,100 $\mathrm{rpm} / \mathrm{min}$ for $5 \mathrm{~min}$ (Beckman Coulter, Inc., Brea, CA, USA), the supernatant was transferred into a sterilized eppendorf tube. The contents of NSE, S-100 $\beta$ and IL-1 $\beta$, IL- 6 and TNF- $\alpha$ in serum were measured by ELISA according to the instruction of the corresponding kit (R\&D Systems, Inc., Minneapolis, MN, USA).

Western blot analysis of $N F-\kappa B / M A P K$ pathway-associated

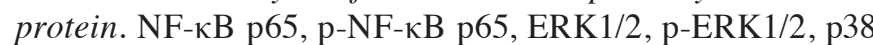
MAPK and p-p38 MAPK were detected in the rat brain by western blot analysis. The total protein was extracted according to the kit instructions. The protein concentration was determined by BCA protein quantification kit (Pierce Biotechnology, Inc., Rockford, IL, USA). Basically, $40 \mu \mathrm{g}$ total proteins were separated by SDS-PAGE and then transferred to a $0.2 \mu \mathrm{m}$ PVDF membrane (GE Healthcare Bio-Sciences, Pittsburgh, PA, USA ). Then the membranes were blocked with $5 \%$ skimmed milk in Tris-buffered saline (TBS) containing $0.1 \%$ Tween-20 (TBS-T), and then incubated overnight at $4^{\circ} \mathrm{C}$ with the respective primary antibodies-rabbit anti-mouse $\mathrm{NF}-\kappa \mathrm{B}$ p65 antibody, rabbit anti-rat p-NF- $\mathrm{B}$ p65 antibody, mouse anti-human ERK1/2 polyclonal antibody, mouse anti-human p-ERK1/2 polyclonal antibodies (Santa Cruz Biotechnology, Inc., Dallas, TX, USA), rabbit anti-human p38 MAPK polyclonal antibody, rabbit anti-human p-p38 MAPK polyclonal antibody, and rabbit anti-human $\beta$-actin polyclonal antibody (Aosen Biological Technology Co., Ltd., Beijing, China). After washing with TBS-T for $30 \mathrm{~min}$ at room temperature, the membrane was further incubated with corresponding horseradish peroxidase-conjugated secondary antibodies for $1 \mathrm{~h}$ at $37^{\circ} \mathrm{C}$. Lastly, protein bands were visualized with Amersham ECL substrates (GE Healthcare Bio-Sciences). The relative abundances of target proteins were measured by Image analysis. $\beta$-actin was used as internal reference.

Statistical analysis. Results were analyzed by SPSS 19.0 statistical software. Statistical data were expressed as mean \pm standard deviation, multiple comparison between the use of one-way ANOVA. Homogeneity of variance was tested with least significant difference. If not homogeneous of variance, the data was converted to homogeneity and then tested with above analysis. $\mathrm{P}<0.05$ was considered to be statistically significant.

\section{Results}

Andrographolide improved the learning ability in postoperative rats. In order to test the leaning ability after surgery, the MWM test was applied to the rats. The results were shown in Fig. 1. During the 6-day water maze positioning navigation training, the mean escape latency to find the platform for the rats was significantly shortened with the training sessions number-dependent manner. The control group was reduced from 49.74 to $12.80 \mathrm{sec}$, the model group from 51.29 to $41.61 \mathrm{sec}$, and the andrographolide group from 50.63 to $19.56 \mathrm{sec}$. From day 2, compared with the control group, the escape latency in the model group and the andrographolide group was significantly prolonged (day 2 is $48.48,46.35$ vs. $34.66 \mathrm{sec}$; day 4 is 43.18 , 31.92 vs. $20.08 \mathrm{sec}, \mathrm{P}<0.05)$. From day 2, compared with the model group, the escape latency of the andrographolide group was significantly shorter than that of the model group (day 3 is 45.61 vs. $37.57 \mathrm{sec}$; day 5 is 43.36 vs. $22.75 \mathrm{sec}, \mathrm{P}<0.05)$. Therefore, andrographolide treatment can significantly improve the learning ability after surgery in rats.

Andrographolide improved the memory ability in postoperative rats. Next, the memory ability was examined in these 2 different groups. The results were shown in Table I. In the space exploration experiment, the number of cross-platform in the model group and the andrographolide group (1.63, 3.17 times), platform quadrant dwelling time $(24.67,32.81 \mathrm{sec})$ was significantly reduced than the control group (4.55 times, $50.39 \mathrm{sec})$, while the swimming distance $(16.32,10.18 \mathrm{~cm})$ was markedly further than the control group $(7.04 \mathrm{~cm})$ 


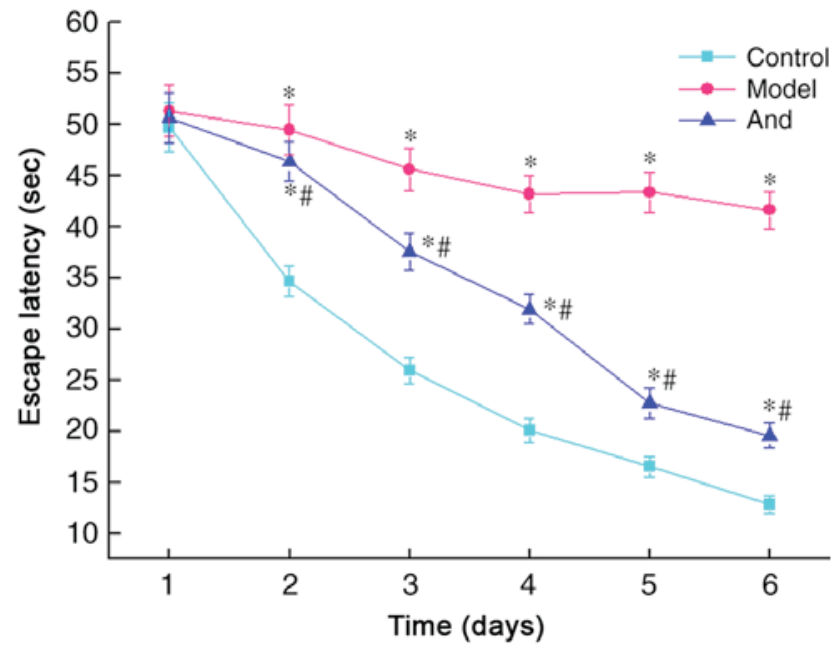

Figure 1. Changes of escape latency in positioning navigation training of the rats after surgery. ${ }^{*} \mathrm{P}<0.05$ vs. control group; ${ }^{\prime} \mathrm{P}<0.05$ vs. model group. And, andrographolide.

$(\mathrm{P}<0.05)$. After treatment with andrographolide, the numbers of cross-platform and platform quadrant retention time in rats in the model group were significantly higher than those in the model group $(\mathrm{P}<0.05)$, while swimming distance was significantly shortened $(\mathrm{P}<0.05)$. Therefore, andrographolide can improve the memory ability in rats after surgery.

Andrographolide ameliorated hippocampal neurons injuries in postoperative rats. To examine the histologic change after surgery for the rats in these 3 groups, the brain tissue slides were observed under an optical microscope after HE staining. The results were as shown in Fig. 2. In the control group, the neurons in the hippocampal CA1 area were neatly arranged and the staining is clear and unevenly. However, the neurons in the model group were scattered, irregular and unevenly stained. Compared with the model group, the neurons in the CA1 region of the hippocampus in andrographolide group were arranged regularly and neatly, the structure was clear and the staining was evenly. These results suggested andrographolide can ameliorate the damages caused by the surgery in hippocampal neurons.

Andrographolide inhibited NSE, S-100 $\beta$ expression and the inflammation factors of $I L-1 \beta, I L-6$ and TNF- $\alpha$ in serum in postoperative rats. To see whether the inflammation reaction exist in these rats after surgery, the ELISA was performed and the results were shown in Fig. 3. The levels in model group and andrographolide group of NSE (18.53, $12.63 \mathrm{ng} / \mathrm{ml}), \mathrm{S}-100 \beta$ $(0.82,0.59 \mathrm{ng} / \mathrm{ml})$ and inflammatory factors of $\mathrm{L}-1 \beta(161.27$, $122.60 \mathrm{ng} / \mathrm{l}), \mathrm{IL}-6(145.83,109.80 \mathrm{ng} / \mathrm{l})$ and TNF- $\alpha(246.53$, $183.72 \mathrm{ng} / \mathrm{l})$ were significantly higher than those in the control group $(7.14,0.38,80.43,64.77,124.91 \mathrm{ng} / \mathrm{ml})$ in rat serum $(\mathrm{P}<0.05)$. After andrographolide treatment, the above proteins and inflammation factors in model group markedly declined $(\mathrm{P}<0.05)$. These results suggested that andrographolide inhibited NSE, S-100 $\beta$ expression and the inflammation factors of IL-1 $\beta$, IL-6 and TNF- $\alpha$ in rat serum.

Andrographolide reduced $N F-\kappa B / M A P K$ pathway-associated protein expressions in postoperative rats. To further

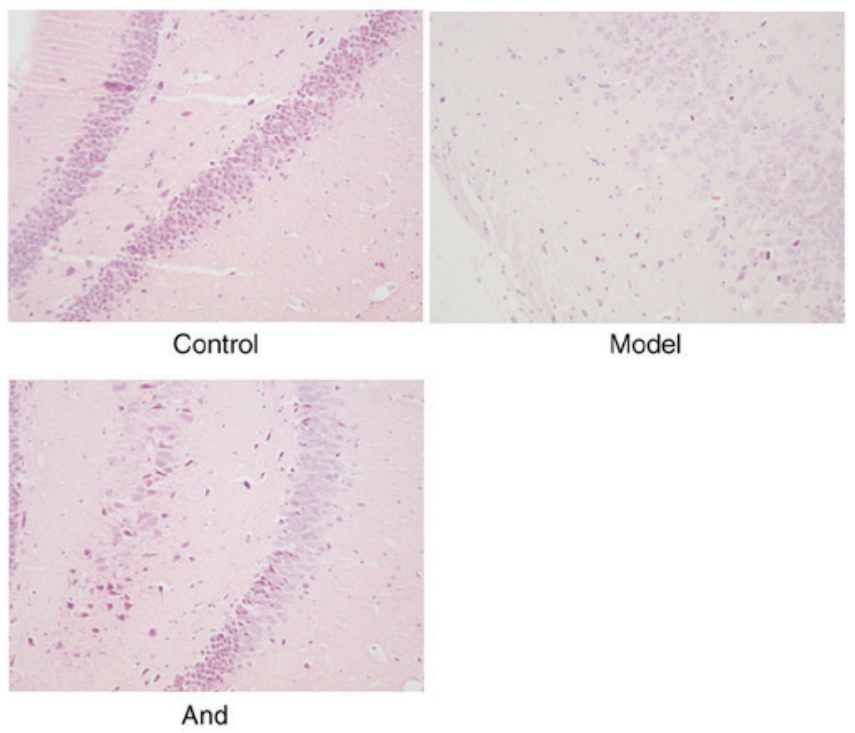

Figure 2. Comparison of neuronal changes in hippocampus in postoperative rats in each group (magnification, x100). And, andrographolide.

detect the involvement of NF- $\mathrm{NB} / \mathrm{MAPK}$ pathway and its associated proteins expression in the rats postoperatively. Immunoblotting was performed. The results were shown in Fig. 4. Compared with control group, the expression level in model group and the andrographolide groupof $\mathrm{NF}-\kappa \mathrm{B}$ p 65 (1.70 eq, 1.30 eq), p-NF-кB p65 (1.72 eq, 1.34 eq), ERK1/2 (1.31 eq, 1.17 eq), p-ERK1/2 (1.54 eq, 1.29 eq), p38 MAPK (1.44 eq, 1.22 eq), p-p38 MAPK (1.83 eq, 1.57 eq) were robustly elevated and difference was significant $(\mathrm{P}<0.05)$. After treatment with andrographolide, even the protein expression was significantly decreased $(\mathrm{P}<0.05)$, still significantly higher than that in control group $(\mathrm{P}<0.05)$. Therefore, andrographolide reduced $\mathrm{NF}-\kappa \mathrm{B} / \mathrm{MAPK}$ pathway-associated protein expressions.

\section{Discussion}

Most of the POCD reports are focusing on cardiac surgeries corroborating a significant proportion of patients with memory, attention, motor speed and mental reaction, and troubles in learning (27). Prior studies found that the effects of stomach surgery seem restricted to hippocampal dependent tasks and hippocampal brain regions (4). In juxtapose, cardiac surgery seems linked with another pattern of cognitive weakening, including learning, spatial memory and object identification, an elongated growth in systemic neutrophil gelatinase-associated lipocalin (NGAL) levels, and more wide range adaptations in the brain involving the hypothalamus, hippocampus and prefrontal cortex (28). Our present study was directed to gauge the cognitive performances in the senior rats experiencing non-cardiac surgery following GA and RA. Specifically, we analyzed the histological alterations in neuronal cells in the hippocampus and the possible NF- $\mathrm{NB} / \mathrm{MAPK}$ pathway and its associated inflammation factors change after treatment with andrographolide in postoperative rats, and we found the similar functions of andrographolide on the non-cardiac surgery animals and the models mentioned above (12-26). These results implied 

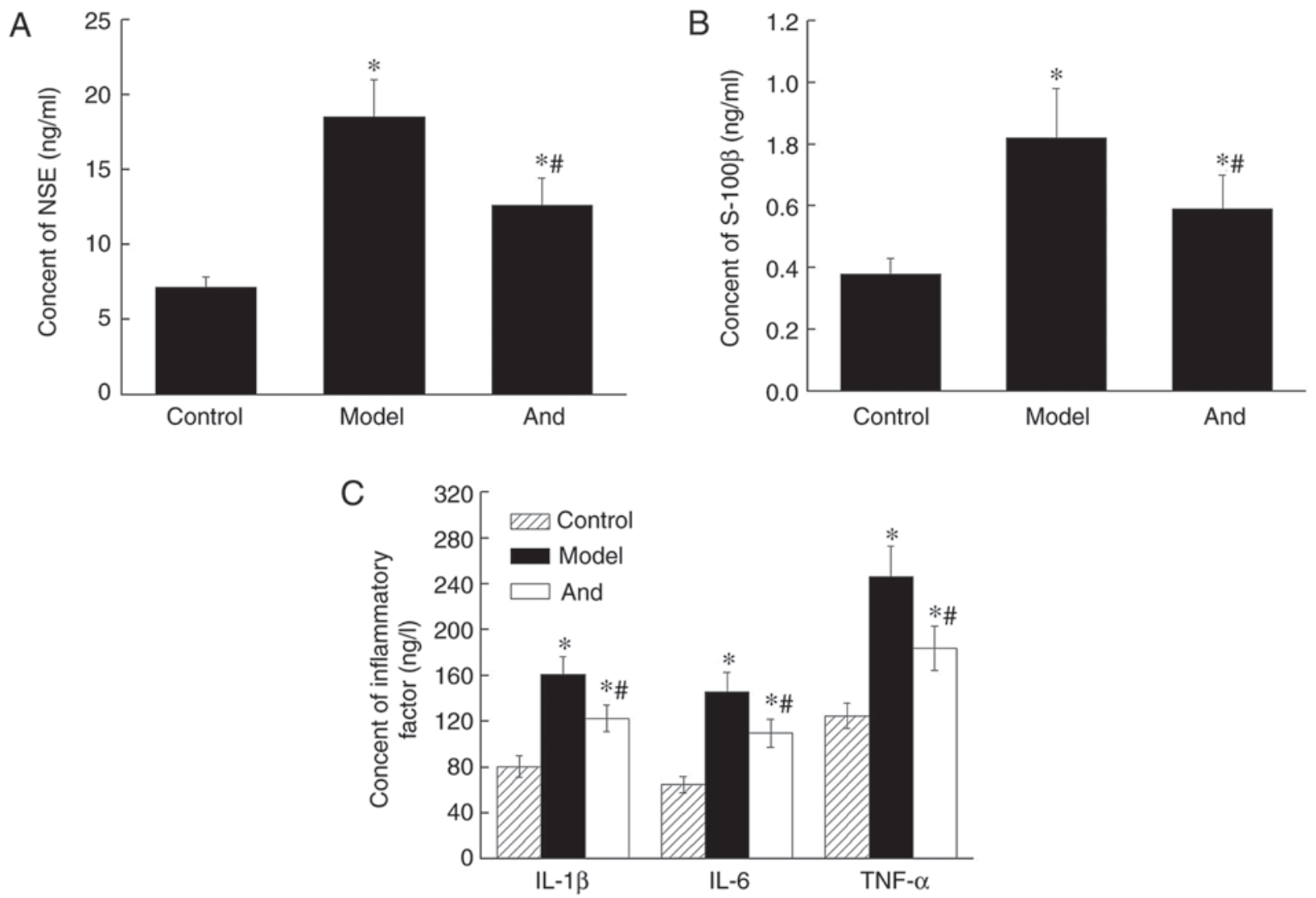

Figure 3. Effects of andrographolide on serum NSE, S-100 $\beta$ and the related inflammatory factors in postoperative rat. (A) NSE content changes in serum. (B) $\mathrm{S}-100 \beta$ content changes in serum. (C) Inflammatory cytokines IL-1 $\beta$, IL-6, TNF- $\alpha$ content changes in serum. ${ }^{*} \mathrm{P}<0.05$ vs. control group; ${ }^{*} \mathrm{P}<0.05$ vs. model group. NSE, neuron-specific enolase; S-100 $\beta$, human soluble protein-100 $\beta$; IL, interluekin; And, andrographolide.
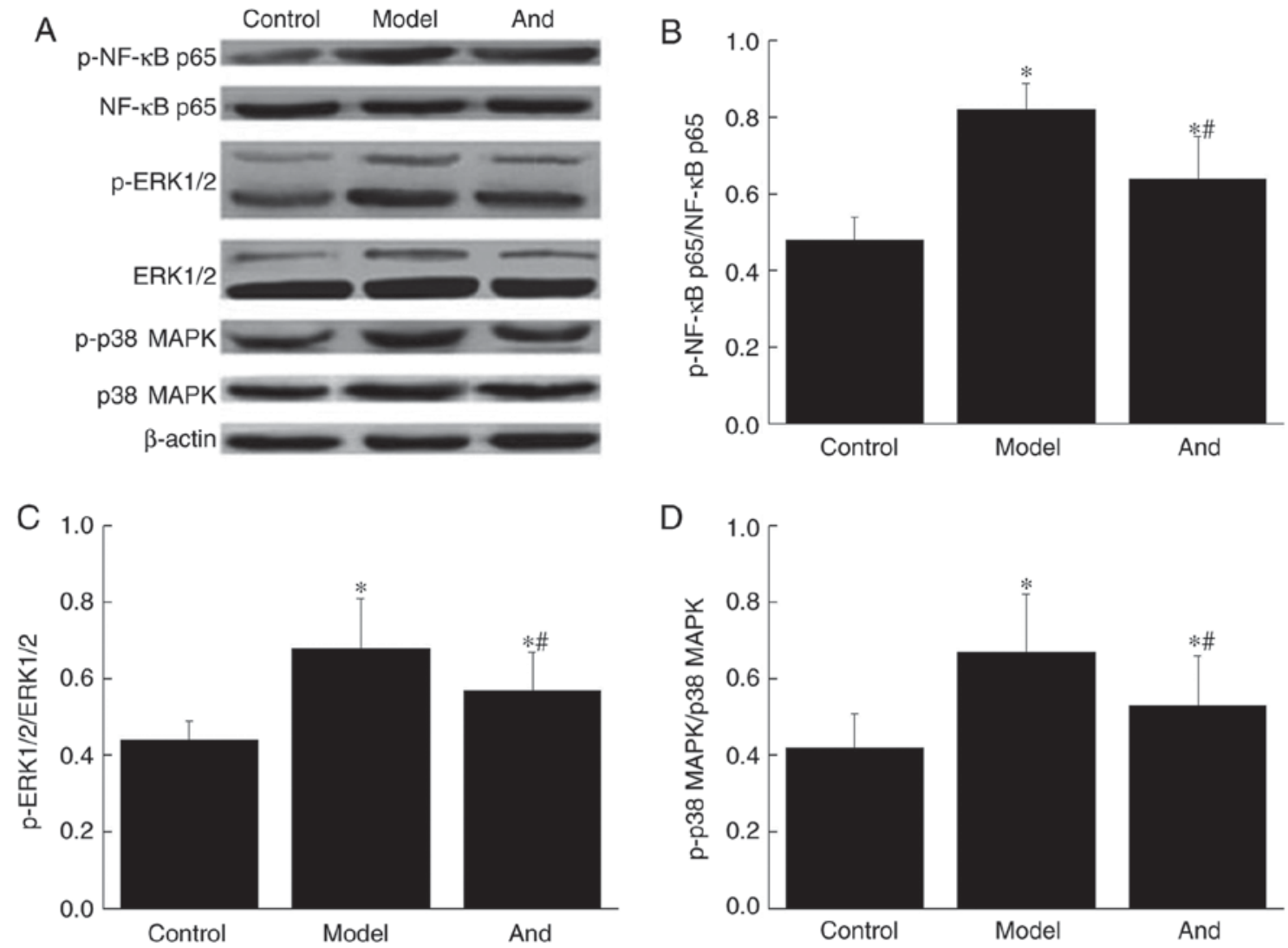

Figure 4. Effects of andrographolide on expression of NF-кB/MAPK pathway-associated proteins. (A and B) Protein band; (C and D) protein column. "P<0.05 vs. control group; ${ }^{~} \mathrm{P}<0.05$ vs. model group. NF- $\mathrm{KB}$, nuclear factor $\kappa \mathrm{B} ;$ MAPK, mitogen-activated protein kinase; $\mathrm{p}-$, phosphorylated, And, andrographolide. 
a common mechanism may exist for the andrographolide on the animals under stress environments.

NSE is a dimeric isoenzyme of the glycolytic enzyme enolase and is mainly found in the neurons (29). Ectopic expression of NSE is used as an auxiliary test in diagnosis of small cell carcinoma of lung, neuroendocrine tumors and Alzheimer's disease (30-32). The $\mathrm{S} 100$ proteins are characterized as a family of low-molecular-weight calcium-binding proteins which was found in glial cells of the central, peripheral nervous system and definitive of two calcium-binding sites that have helix-loop-helix ('EF-hand type') conformation (33), which is mainly expressed in astrocytes and on the neuronal plasma membrane (34). The $\mathrm{S}-100 \beta$ level in serum elevation is seen in traumatic brain injury, cerebral infarction, traumatic brain injury, subarachnoid hemorrhage or cerebral infarction (35). The serum levels of NSE and S-100 $\beta$ are increased after various types of brain damage, such as focal and global ischemia, head injury and hemorrhagic brain damage (36). It has been shown that NSE positively correlated with infarct volume in ACI patients, and NSE and S-100 $\beta$ protein levels can be used to predict the clinical outcome of acute cerebral infarction (ACI) (37). Our results confirmed the uprising of NSE and S-100 $\beta$ in postoperative rats, and more importantly, extend the knowledge of downregulation by andrographolide of NSE and S-100 $\beta$ postoperatively.

As known, the NF- $\kappa \mathrm{B}$ activation by LPS mediated the expression of proinflammatory cytokines and played an important role in many inflammatory diseases (38). Other studies proved andrographolide can bind to p50 to inhibit $\mathrm{NF}-\kappa \mathrm{B}$ activation (24). In line with that, our results here also favored that andrographolide treatment reduced the phosphorylation of MAPK and NF- $\mathrm{B}$ which suggest that andrographolide may exert on the very upstream of MAPK and NF- $\kappa$ B. Combining the results of NSE and S-100 $\beta$, histology observation and MAPK and $N F-\kappa B$ signaling pathway alteration, it is fair to assume that andrographolide may play critical role in therapeutic application for the surgery-related patients. However, the common mechanism of andrographolide on the POCD need to be further validated.

To our knowledge, this is the first time to report the effect of andrographolide on the POCD and the association with NF- $\kappa$ B/MAPK pathway. Based on our investigation, we carefully concluded that andrographolide may ameliorate the POCD in aged rats after surgery. The underlying mechanism may associate with downregulation the inflammatory factors and NF- $\mathrm{N} / \mathrm{MAPK}$-associated protein expression. These data may represent a new therapeutic application of andrographolide in the prevention and treatment of POCD in advanced age patients. However, the clinical applicability of these experimental outcomes are yet to be determined. The translational methodologies are designated to define the role of inflammation as a conceivable contributing consideration in the highly advanced patients.

\section{Acknowledgements}

The present study was supported by Traditional Chinese Medicine Science and Technology Development of Project of Shandong Province, China (grant no. 2015-416), and National Science Foundation of Shandong Province, China (grant no. ZR2016HL17).

\section{References}

1. Rundshagen I: Postoperative cognitive dysfunction. Dtsch Arztebl Int 111: 119-125, 2014.

2. Bedford PD: Adverse cerebral effects of anaesthesia on old people. Lancet 269: 259-263, 1955.

3. Krenk L, Rasmussen LS and Kehlet H: New insights into the pathophysiology of postoperative cognitive dysfunction. Acta Anaesthesiol Scand 54: 951-956, 2010.

4. Hovens IB, van Leeuwen BL, Mariani MA, Kraneveld AD and Schoemaker RG: Postoperative cognitive dysfunction and neuroinflammation; cardiac surgery and abdominal surgery are not the same. Brain Behav Immun 54: 178-193, 2016.

5. Rasmussen LS: Postoperative cognitive dysfunction: Incidence and prevention. Best Pract Res Anaesthesiol 20: 315-330, 2006.

6. Selnes OA, McKhann GM, Borowicz LM Jr and Grega MA: Cognitive and neurobehavioral dysfunction after cardiac bypass procedures. Neurol Clin 24: 133-145, 2006.

7. Evered L, Silbert B, Scott DA, Ames D, Maruff P and Blennow K: Cerebrospinal fluid biomarker for Alzheimer disease predicts postoperative cognitive dysfunction. Anesthesiology 124: 353-361, 2016.

8. Arora SS, Gooch JL and Garcia PS: Postoperative cognitive dysfunction, Alzheimer's disease, and anesthesia. Int $\mathrm{J}$ Neurosci 124: 236-242, 2014.

9. Hussain M, Berger M, Eckenhoff RG and Seitz DP: General anesthetic and the risk of dementia in elderly patients: Current insights. Clin Interv Aging 9: 1619-1628, 2014.

10. Finnerty CC, Mabvuure NT, Ali A, Kozar RA and Herndon DN: The surgically induced stress response. JPEN J Parenter Enteral Nutr 37 (5 Suppl): 21S-29S, 2013.

11. van Harten AE, Scheeren TW and Absalom AR: A review of postoperative cognitive dysfunction and neuroinflammation associated with cardiac surgery and anaesthesia. Anaesthesia 67: 280-293, 2012.

12. Hovens IB, Schoemaker RG, van der Zee EA, Absalom AR, Heineman E and van Leeuwen BL: Postoperative cognitive dysfunction: Involvement of neuroinflammation and neuronal functioning. Brain Behav Immun 38: 202-210, 2014.

13. Barrientos RM, Hein AM, Frank MG, Watkins LR and Maier SF: Intracisternal interleukin-1 receptor antagonist prevents postoperative cognitive decline and neuroinflammatory response in aged rats. J Neurosci 32: 14641-14648, 2012.

14. Cibelli M, Fidalgo AR, Terrando N, Ma D, Monaco C, Feldmann M, Takata M, Lever IJ, Nanchahal J, Fanselow MS and Maze M: Role of interleukin-1beta in postoperative cognitive dysfunction. Ann Neurol 68: 360-368, 2010.

15. Jiang $\mathrm{P}$, Ling $\mathrm{Q}, \mathrm{Liu} \mathrm{H}$ and $\mathrm{Tu} \mathrm{W}$ : Intracisternal administration of an interleukin-6 receptor antagonist attenuates surgery-induced cognitive impairment by inhibition of neuroinflammatory responses in aged rats. Exp Ther Med 9: 982-986, 2015.

16. Wan Y, Xu J, Ma D, Zeng Y, Cibelli M and Maze M: Postoperative impairment of cognitive function in rats: A possible role for cytokine-mediated inflammation in the hippocampus. Anesthesiology 106: 436-443, 2007.

17. Terrando N, Monaco C, Ma D, Foxwell BM, Feldmann M and Maze M: Tumor necrosis factor-alpha triggers a cytokine cascade yielding postoperative cognitive decline. Proc Natl Acad Sci USA 107: 20518-20522, 2010.

18. Peng L, Xu L and Ouyang W: Role of peripheral inflammatory markers in postoperative cognitive dysfunction (POCD): A meta-analysis. PLoS One 8: e79624, 2013.

19. Yirmiya R and Goshen I: Immune modulation of learning, memory, neural plasticity and neurogenesis. Brain Behav Immun 25: 181-213, 2011.

20. Tang JX, Baranov D, Hammond M, Shaw LM, Eckenhoff MF and Eckenhoff RG: Human Alzheimer and inflammation biomarkers after anesthesia and surgery. Anesthesiology 115: 727-732, 2011.

21. Cortese GP, Barrientos RM, Maier SF and Patterson SL: Aging and a peripheral immune challenge interact to reduce mature brain-derived neurotrophic factor and activation of TrkB, PLCgamma1, and ERK in hippocampal synaptoneurosomes. J Neurosci 31: 4274-4279, 2011.

22. Fidalgo AR, Cibelli M, White JP, Nagy I, Noormohamed F, Benzonana L, Maze M and Ma D: Peripheral orthopaedic surgery down-regulates hippocampal brain-derived neurotrophic factor and impairs remote memory in mouse. Neuroscience 190: 194-199, 2011. 
23. Wintachai P, Kaur P, Lee RC, Ramphan S, Kuadkitkan A, Wikan N, Ubol S, Roytrakul S, Chu JJ and Smith DR: Activity of andrographolide against chikungunya virus infection. Sci Rep 5: 14179, 2015.

24. Peng S, Hang N, Liu W, Guo W, Jiang C, Yang X, Xu Q and Sun Y: Andrographolide sulfonate ameliorates lipopolysaccharide-induced acute lung injury in mice by down-regulating MAPK and NF-кB pathways. Acta Pharm Sin B 6: 205-211, 2016.

25. Zhu T, Wang DX, Zhang W, Liao XQ, Guan X, Bo H, Sun JY, Huang NW, He J, Zhang YK, et al: Andrographolide protects against LPS-induced acute lung injury by inactivation of NF- $\kappa \mathrm{B}$. PLoS One 8: e56407, 2013.

26. Li FX and Li SS: Effects of andrographolide on the activation of mitogen activated protein kinases and nuclear factor- $\kappa \mathrm{B}$ in mouse peritoneal macrophage-derived foam cells. Chin J Integr Med 18: 391-394, 2012.

27. Kotekar N, Kuruvilla CS and Murthy V: Post-operative cognitive dysfunction in the elderly: A prospective clinical study. Indian J Anaesth 58: 263-268, 2014

28. Hovens IB, van Leeuwen BL, Nyakas C, Heineman E, van der Zee EA and Schoemaker RG: Postoperative cognitive dysfunction and microglial activation in associated brain regions in old rats. Neurobiol Learn Mem 118: 74-79, 2015.

29. Zaheer S, Beg M, Rizvi I, Islam N, Ullah E and Akhtar N Correlation between serum neuron specific enolase and functional neurological outcome in patients of acute ischemic stroke. Ann Indian Acad Neurol 16: 504-508, 2013.

30. Song WA, Liu X, Tian XD, Wang W, Liang CY, Zhang T, Guo JT, Peng $\mathrm{YH}$ and Zhou NK: Utility of squamous cell carcinoma antigen, carcinoembryonic antigen, Cyfra 21-1 and neuron specific enolase in lung cancer diagnosis: A prospective study from China. Chin Med J (Engl) 124: 3244-3248, 2011.

31. Yao JC, Pavel M, Phan AT, Kulke MH, Hoosen S, St Peter J, Cherfi A and Öberg KE: Chromogranin A and neuron-specific enolase as prognostic markers in patients with advanced pNET treated with everolimus. J Clin Endocrinol Metab 96: 3741-3749, 2011.
32. Schmidt FM,MerglR,Stach B,Jahn I, GertzHJ and SchönknechtP: Elevated levels of cerebrospinal fluid neuron-specific enolase (NSE) in Alzheimer's disease. Neurosci Lett 570: 81-85, 2014

33. Neselius $\mathrm{S}$, Brisby $\mathrm{H}$, Theodorsson A, Blennow K, Zetterberg $\mathrm{H}$ and Marcusson J: CSF-biomarkers in Olympic boxing: Diagnosis and effects of repetitive head trauma. PLoS One 7: e33606, 2012.

34. Mondello S, Linnet A, Buki A, Robicsek S, Gabrielli A, Tepas J, Papa L, Brophy GM, Tortella F, Hayes RL and Wang KK: Clinical utility of serum levels of ubiquitin C-terminal hydrolase as a biomarker for severe traumatic brain injury. Neurosurgery 70 : 666-675, 2012.

35. Zurek J and Fedora M: The usefulness of S100B, NSE, GFAP, NF-H, secretagogin and Hsp70 as a predictive biomarker of outcome in children with traumatic brain injury. Acta Neurochir (Wien) 154: 93-103, 2012.

36. Palmio J, Huuhka M, Laine S, Huhtala H, Peltola J, Leinonen E, Suhonen $J$ and Keränen T: Electroconvulsive therapy and biomarkers of neuronal injury and plasticity: Serum levels of neuron-specific enolase and S-100b protein. Psychiatry Res 177: 97-100, 2010

37. González-García S, González-Quevedo A, FernándezConcepción O, Peña-Sánchez M, Menéndez-Saínz C, HernándezDíaz Z, Arteche-Prior M, Pando-Cabrera A and FernándezNovales C: Short-term prognostic value of serum neuron specific enolase and S100B in acute stroke patients. Clin Biochem 45: 1302-1307, 2012.

38. Yamauchi S, Ito $\mathrm{H}$ and Miyajima A: IkappaBeta, a nuclear IkappaB protein, positively regulates the NF-kappaB-mediated expression of proinflammatory cytokines. Proc Natl Acad Sci USA 107: 11924-11929, 2010 